\title{
Clozapine is associated with secondary antibody deficiency
}

Mark Ponsford, Daniel Castle, Tayyeb Tahir, Rebecca Robinson, Wendy Wade, Rachael Steven, Kathryn Bramhall, Mo Moody, Emily Carne, Catherine Ford, Daniel Farewell, Paul Williams, Tariq El-Shanawany and Stephen Jolles

\section{Background}

Schizophrenia affects $1 \%$ of the population. Clozapine is the only medication licensed for treatment-resistant schizophrenia and is intensively monitored to prevent harm from neutropenia. Clozapine is also associated with increased risk of pneumonia although the mechanism is poorly understood.

\section{Aims}

To investigate the potential association between clozapine and antibody deficiency.

\section{Methods}

Patients taking clozapine and patients who were clozapine-naive and receiving alternative antipsychotics were recruited and completed a lifestyle, medication and infection-burden questionnaire. Serum total immunoglobulins (immunoglobulin (Ig)G, $\operatorname{IgA}, \operatorname{IgM}$ ) and specific IgG antibodies to haemophilus influenzae type B, tetanus and IgG, IgA and IgM to pneumococcus were measured.

\section{Results}

Immunoglobulins were all significantly reduced in the clozapinetreated group ( $n=123$ ) compared with the clozapine-naive group $(n=111)$. Odds ratios (ORs) for a reduction in clozapine:control immunoglobulin values below the fifth percentile were $\operatorname{lgG}, \mathrm{OR}=$ 6.00 (95\% Cl 1.31-27.44); IgA, OR= 16.75 (95\% Cl 2.18-128.60); and $\operatorname{IgM}, \mathrm{OR}=3.26$ (95\% Cl 1.75-6.08). These findings remained significant despite exclusion of other potential causes of hypogammaglobulinaemia. In addition, duration on clozapine was associated with decline in IgG. A higher proportion of the clozapine-treated group reported taking more than five courses of antibiotics in the preceding year $(5.3 \%(n=5)$ versus $1 \%(n=1)$.

\section{Conclusions}

Clozapine use was associated with significantly reduced immunoglobulin levels and an increased proportion of patients using more than five antibiotic courses in a year. Antibody testing is not included in existing clozapine monitoring programmes but may represent a mechanistic explanation and modifiable risk factor for the increased rates of pneumonia and sepsis-related mortality previously reported in this vulnerable cohort.

\section{Declaration of interest}

S.J. has received support from CSL Behring, Shire, LFB, Biotest, Binding Site, Sanofi, GSK, UCB Pharma, Grifols, BPL SOBI, Weatherden, Zarodex and Octapharma for projects, advisory boards, meetings, studies, speaker and clinical trials.

\section{Keywords}

Clozapine; schizophrenia; pneumonia; secondary antibody deficiency; vaccination.

\section{Copyright and usage}

(C) The Royal College of Psychiatrists 2018. This is an Open Access article, distributed under the terms of the Creative Commons Attribution-NonCommercial-ShareAlike licence (http://creativecommons.org/licenses/by-nc-nd-sa/4.0/), which permits noncommercial re-use, distribution, and reproduction in any medium, provided the same Creative Commons licence is included and the original work is properly cited. The written permission of Cambridge University Press must be obtained for commercial re-use.
Schizophrenia affects around $1 \%$ of the population and approximately $30 \%$ of patients have treatment-resistant schizophrenia for which clozapine is the only licensed medication. In addition to debilitating psychiatric symptoms it is associated with an unemployment rate of $80-90 \%$ and a life expectancy reduced by 10-20 years. ${ }^{1}$ Approximately $5 \%$ of those diagnosed with schizophrenia die by suicide. ${ }^{2}$ Although clozapine reduces overall mortality in severe schizophrenia, ${ }^{3}$ it is associated with a number of often poorly understood side-effects with a growing body of evidence linking clozapine with elevated rates of pneumonia-related admission and mortality. ${ }^{4-9}$ Mortality from respiratory infections/sepsis despite intensive monitoring is a common reason for discontinuing treatment. ${ }^{10,11}$ Various mechanisms for the increase in pneumonia have been suggested, including aspiration, sialorrhoea and impairment of swallowing function with oesophageal dilatation and hypomotility as well as agranulocytosis ${ }^{12}$ and smoking. ${ }^{13}$ The possibility of a link between antibody deficiency and clozapine use was first raised during a study of population screening for antibody deficiency using calculated globulin screening in Wales. ${ }^{14}$ Calculated globulin is derived from the difference between total serum protein and albumin concentrations, part of the liver function test profile. Immunoglobulins form a significant proportion of the globulin fraction and therefore low calculated globulin may indicate antibody deficiency. ${ }^{14,15}$ Antibody deficiency is not a listed clozapine side-effect and is not a part of current clozapine monitoring. To further assess a possible association between antibody deficiency and clozapine use we undertook a cross-sectional case-control study to compare the immunoglobulin levels and specific antibody levels in patients taking either clozapine or alternative antipsychotics.

\section{Method}

\section{Participants}

Adults (>18 years) receiving either clozapine or non-clozapine antipsychotics were recruited during routine clinic visits to ten community mental health team out-patient clinics in Cardiff \& Vale and Cwm Taf Health Boards by specialist research officers between November 2013 and December 2016. All potential participants were given the same participant information leaflet to read that outlined the purpose of the study and indicated that they would be asked some questions about their health and have a single $(4 \mathrm{~mL})$ blood sample taken. Following consent, participants completed the short lifestyle, drug history and infection questionnaire followed 


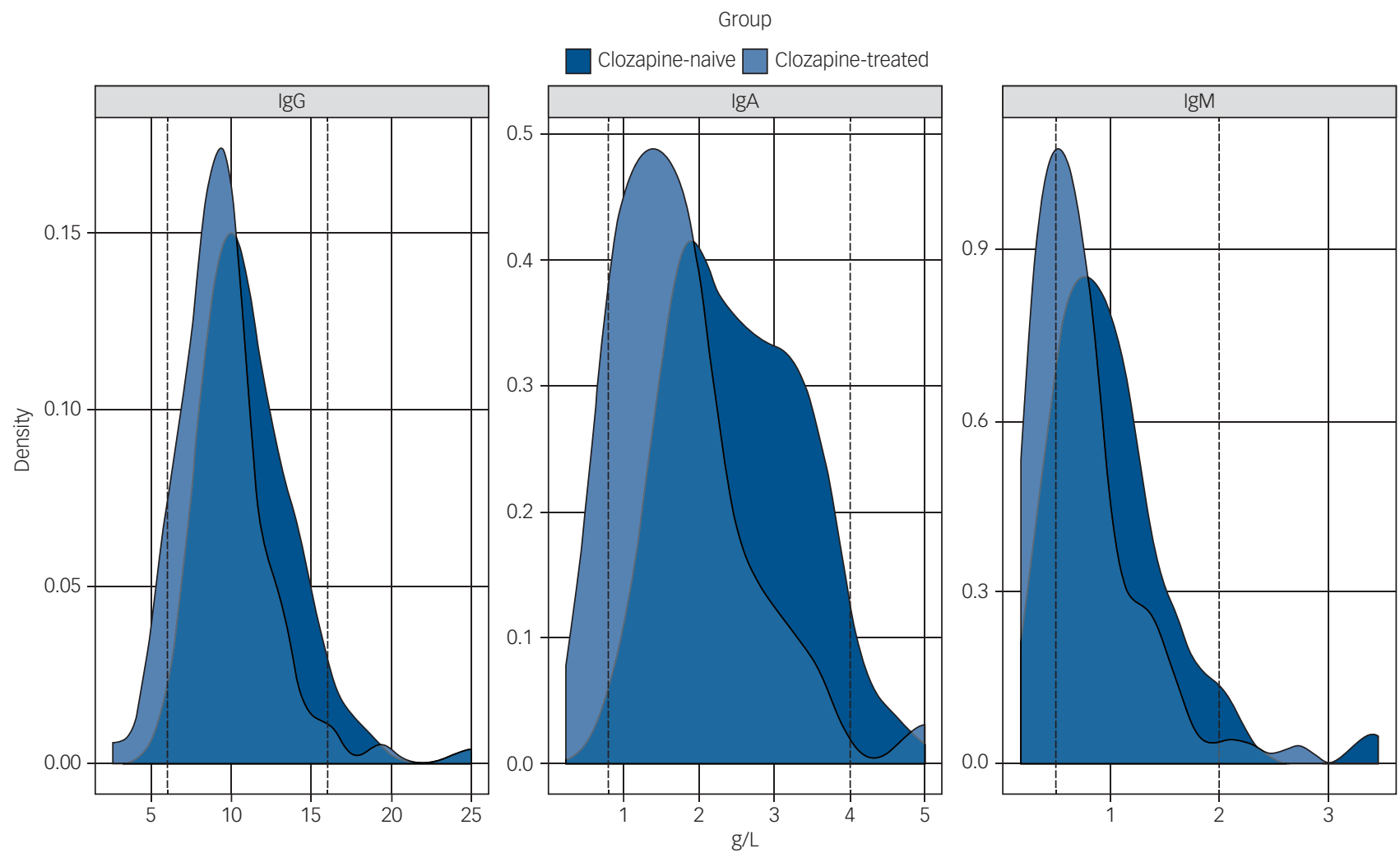

Fig. 1 Immunoglobulin levels in the clozapine-treated and clozapine-naive groups.

The distribution of the serum levels of immunoglobulin (Ig)G, IgA and IgM for the clozapine-treated (light blue, $n=94$ ) and clozapine-naive (dark

blue, $n=98$ ) groups are shown with the laboratory 5th and 95th percentile of the reference ranges for a healthy adult population represented as vertical dotted lines. The differences between the median IgG, IgA and IgM levels for the clozapine-treated versus clozapine-naive groups are all significant $(P<0.0001)$

by blood sampling. Where required, drug histories were confirmed with the patient's general practice records. Formal psychiatric diagnoses and antipsychotic medication use were confirmed using the medical notes, in line with other studies. Patients' admission rates were confirmed by electronic review for all patients in the postexclusion group over the 12-month period prior to recruitment and assessed for an infective trigger.

\section{Measurements}

Immunoglobulin levels (immunoglobulin (Ig)G, IgA and IgM) were assayed by nephelometry (Siemens BN2 Nephelometer; Siemens), serum electrophoresis (Sebia Capillarys 2; Sebia, Norcross, GA, USA) and, where appropriate, serum immunofixation (Sebia Hydrasys; Sebia, Norcross, GA, USA). Where immunoglobulin was detectable, the lower limit of assay sensitivity (IgG, $1.34 \mathrm{~g} / \mathrm{L}$; $\operatorname{IgA}, 0.24 \mathrm{~g} / \mathrm{L}$; and $\operatorname{IgM}, 0.17 \mathrm{~g} / \mathrm{L}$ ) was used for data analysis. Specific antibody titres against haemophilus influenzae, tetanus and pneumococcal capsular polysaccharide were determined by enzyme-linked immunosorbent assay (The Binding Site, Birmingham, UK). All testing was performed in the United Kingdom Accreditation Service accredited Immunology Laboratory at the University Hospital of Wales. Laboratory adult reference ranges for immunoglobulin levels used were, IgG, 6.00-16.00 g/L; IgA, $0.80-4.00 \mathrm{~g} / \mathrm{L} ;$ IgM $0.50-2.00 \mathrm{~g} / \mathrm{L}$.

\section{Statistical analysis}

Statistical analysis of the laboratory and clinical data was performed using Microsoft Excel and Graphpad Prism (version 6.07). Unadjusted odds ratio (ORs) and 95\% confidence intervals were calculated using Fisher's exact test for the number of individuals with an immunoglobulin value below the lower limit of normal (IgG $<6.00 \mathrm{~g} / \mathrm{L}, \operatorname{IgA}<0.80 \mathrm{~g} / \mathrm{L}$ and $\operatorname{IgM}<0.50 \mathrm{~g} / \mathrm{L}$ ). As the distribution of all three immunoglobulin classes in the study population differed from a Gaussian distribution (Fig. 1), non-parametric Mann-Whitney $U$-testing was performed. Specific antibody titres, antibiotics and admission frequencies were similarly evaluated. No validated protective values are currently available for pneumococcal-specific IgA or IgM as a relevant threshold, and odds ratios were not calculated.

To adjust for factors, other than clozapine treatment (age, gender, diabetes, asthma/chronic obstructive pulmonary disease (COPD), second antipsychotic, diagnosis of schizophrenia and duration of clozapine therapy) that might influence immunoglobulin levels, linear regression analysis was performed in $\mathrm{R}$ (version 3.4.0). These models included a term corresponding to a global difference in levels between the two groups and, by way of an interaction with treatment duration, a term corresponding to a reduction in immunoglobulin levels per year on clozapine or other antipsychotic.

The study received ethical approval from the North West Regional REC committee (REC Reference 13/EM/0209, IRAS ID 104402) and sponsorship from Cardiff \& Vale University Health Board.

\section{Results}

\section{Study participants}

A total of 291 patients taking clozapine and 280 who were clozapine naive were approached and 123 taking clozapine and 113 who were 
Table 1 Study participants and excluded participants

\begin{tabular}{lcc|} 
& $\begin{array}{c}\text { Clozapine } \\
\text { group }\end{array}$ & Control group \\
\hline Total screened, $n$ & 291 & 280 \\
Declined/unable to consent or provide & 168 & 169 \\
$\quad$ serum, $n$ & 123 & 113 \\
Initial cohort, $n$ & 29 & 15 \\
Excluded from subsequent analysis, ${ }^{\text {a }} n$ & 2 & 1 \\
Carbamazepine & 5 & 5 \\
Lamotrigine & 1 & - \\
Levetiracetam & 1 & - \\
Topiramate & 17 & 5 \\
Valproate & 1 & 3 \\
Paraprotein & - & 1 \\
Leflunomide & 1 & - \\
Prior chemotherapy & 1 & - \\
$\quad$ HIV & 94 (32.3) & 98 (35.0) \\
Post-exclusion cohort, $n$ (\% of total & & \\
$\quad$ screened) & & \\
a. Included in initial cohort analysis for total and specific antibody levels and excluded \\
from subsequent analysis after identification of possible causes of secondary hypo- \\
gammaglobulinaemia (European Society of Immunodeficiencies criteria).
\end{tabular}

clozapine naive consented to the study (Table 1). Recruitment was stopped as per protocol when more than 100 patients in each group had been achieved. There were small differences in gender with more men in the clozapine-treated group (53\% versus $50 \%$ ) and a lower mean age in the clozapine group (45 versus 50 years). These differences may reflect the male predominance in schizophrenia and is unlikely to be relevant as there are no gender or age differences in the adult reference range for serum immunoglobulins. ${ }^{16}$

In the post-exclusion cohort, the levels of smoking, diabetes, COPD/asthma, and alcohol intake were similar between the groups (Table 2). As expected almost all $(94 \%, n=88)$ of the patients taking clozapine were diagnosed with schizophrenia or schizoaffective disorder whereas these diagnoses accounted for $64 \%(n=63)$ of those taking other antipsychotic medication in the control group. This reflects the more restricted prescribing indications for clozapine compared with other antipsychotics.

\section{Exclusion of possible confounding medications and diagnoses}

Review of medical records in relation to the European Society of Immunodeficiencies differential diagnosis of hypogammaglobulinaemia ${ }^{17}$ highlighted a number of patients with possible drug or infection-related contributors; including anti-epileptic or mood stabilising medications, previous chemotherapy, presence of paraprotein, or HIV infection who were excluded from the analysis (Table 1).

Median concentrations of serum immunoglobulins for both pre- and post-exclusion patient cohorts receiving clozapine are shown in Table 3 . Patients receiving clozapine showed significantly reduced median concentrations of all three immunoglobulin classes (IgG, IgA and IgM) relative to the clozapine-naive control group. The relative shift in distributions is highlighted in Fig. 1 (post-exclusion groups represented).

The odds ratios for individual patients having an immunoglobulin measured below the lower limit of the reference range are also shown in Table 3. In the post-exclusion groups, $1 \%$ $(n=1)$ of controls and $8.5 \%(n=8)$ of clozapine-treated group had IgG levels $<6.00 \mathrm{~g} / \mathrm{L} ; 13.8 \%(n=13)$ of clozapine and no controls had IgA levels $<0.80 \mathrm{~g} / \mathrm{L}$; and $34 \%(n=32)$ of clozapine and $15.3 \%(n=15)$ of controls had IgM levels $<0.50 \mathrm{~g} / \mathrm{L}$. Furthermore, three patients in the clozapine group had evidence of reduction of all three immunoglobulin classes; two patients had severely
Table 2 Participant characteristics of the post-exclusion cohort

\begin{tabular}{|c|c|c|}
\hline & $\begin{array}{l}\text { Clozapine group } \\
\qquad(n=94)\end{array}$ & $\begin{array}{l}\text { Control group } \\
\qquad(n=98)\end{array}$ \\
\hline Age, years: mean (range) & $44.4(22.0-78.0)$ & $50.4(21.6-78.0)$ \\
\hline Gender, men:women & $64: 30$ & $54: 44$ \\
\hline Dual antipsychotic treatment, $n$ (\%) & $29(30.9)$ & $11(11.2)$ \\
\hline $\begin{array}{l}\text { Duration of antipsychotic use, years: } \\
\text { median (range) }\end{array}$ & $8(0.1-20)$ & $7(0.1-44)$ \\
\hline Current smoking, $n(\%)$ & $57(60.6)$ & $55(56.1)$ \\
\hline Diabetes, $n$ (\%) & $19(20.2)$ & $16(16.3)$ \\
\hline $\begin{array}{l}\text { Chronic obstructive pulmonary } \\
\text { disorder/asthma, } n(\%)\end{array}$ & $12(12.7)$ & $16(16.3)$ \\
\hline $\begin{array}{l}\text { Alcohol intake, units per week: mean } \\
\text { (range) }\end{array}$ & $5.3(0-60)$ & $6.0(0-68)$ \\
\hline \multicolumn{3}{|l|}{ Primary psychiatric diagnosis, $n$} \\
\hline Schizophrenia & 87 & 58 \\
\hline Schizoaffective disorder & 1 & 5 \\
\hline Bipolar & 0 & 11 \\
\hline Psychosis & 0 & 15 \\
\hline Depression & 0 & 3 \\
\hline Personality disorder & 2 & 2 \\
\hline Anxiety disorder & 0 & 2 \\
\hline Electronic record incomplete & 4 & 2 \\
\hline \multicolumn{3}{|l|}{ Antibiotic courses in 12 months, $n$ (\%) } \\
\hline No courses & $57(60.6)$ & $62(63.3)$ \\
\hline $1-5$ courses & $32(34.0)$ & $35(35.7)$ \\
\hline$>5$ courses & $5(5.3)$ & $1(1.0)$ \\
\hline
\end{tabular}

reduced IgG below $4.00 \mathrm{~g} / \mathrm{L}$. The lowest IgG in the clozapine group was $2.59 \mathrm{~g} / \mathrm{L}$, compared with $5.92 \mathrm{~g} / \mathrm{L}$ in the control group. These differences were statistically highly significant $(P<0.017$ or below) despite reduction in sample size, with exclusion of three clozapine-treated individuals with IgG values of 3.19, 4.93 and $5.42 \mathrm{~g} / \mathrm{L}$ (taking concurrent anti-epileptic medications). One patient with an $\mathrm{IgG}$ of $5.79 \mathrm{~g} / \mathrm{L}$ was similarly excluded from the control group. All subsequent analysis of results has been undertaken on the cohort following exclusion of possible confounding medications and diagnoses.

\section{Specific antibody levels are low in both clozapine- treated and clozapine-naive groups}

Large percentages of individuals in both the clozapine-treated and clozapine-naive groups have specific IgG antibody levels below the protective levels for haemophilus influenzae B $(51.1 \%(n=48)$ and $54.1 \%(n=53)$ less than $1 \mathrm{mcg} / \mathrm{mL}$, respectively), ${ }^{24}$ pneumococcus $(52.1 \%(n=49)$ and $54.1 \%(n=53)$ less than $50 \mathrm{mg} / \mathrm{L}$, respectively $)^{18}$ and tetanus $(10.6 \%(n=10)$ and $13.3 \%(n=13)$ less than $0.1 \mathrm{IU} / \mathrm{mL}$, respectively). These were not significantly different using non-parametric testing. In contrast, levels in the clozapine-treated group for pneumococcal-specific IgA were reduced by $28 \mathrm{IU} / \mathrm{mL}$ over the clozapine-naive group $(30.8 \mathrm{U} / \mathrm{mL}$ versus $58.8 \mathrm{U} / \mathrm{mL} P<0.001$ ) and IgM was reduced by $26 \mathrm{IU} / \mathrm{mL}$ (59.8 $\mathrm{U} / \mathrm{mL}$ versus $85.8 \mathrm{U} / \mathrm{mL} P<0.001$ ) perhaps reflecting the observed greater relative reductions in total IgA and IgM levels (supplementary Table 1 available at https://doi.org/10.1192/bjp. 2018.152). It should be noted that although values for protective levels of specific antibodies of haemophilus influenza B $(>1 \mathrm{mcg} / \mathrm{mL})$ and tetanus $(>0.1 \mathrm{IU} / \mathrm{mL})$ are reasonably well-validated there remains ongoing debate regarding the protective levels of pneumococcal antibodies.

\section{Longer duration of clozapine use is associated with increased risk of hypogammaglobulinaemia}

Information on duration of antipsychotic use was available for 88 of the 94 individuals in the clozapine group and 97 of 98 of those in the 
Table 3 Immunoglobulin concentrations and odds ratio for the

clozapine-treated and clozapine-naive groups ${ }^{a}$

\begin{tabular}{|c|c|c|c|}
\hline & $\begin{array}{l}\text { Clozapine } \\
\text { group }\end{array}$ & $\begin{array}{l}\text { Control } \\
\text { group }\end{array}$ & $P$ \\
\hline \multirow{4}{*}{$\begin{array}{l}\text { Pre-exclusion cohort, } n \\
\text { IgG, median } \\
\text { IgA, median } \\
\text { IgM, median }\end{array}$} & 123 & 113 & \\
\hline & 9.31 & 10.6 & $<0.0001^{b}$ \\
\hline & 1.58 & 2.46 & $<0.0001^{b}$ \\
\hline & 0.61 & 0.91 & $<0.0001^{b}$ \\
\hline \multirow{4}{*}{$\begin{array}{l}\text { Post-exclusion cohort, } n \\
\text { IgG, median } \\
\text { IgA, median } \\
\text { IgM, median }\end{array}$} & 94 & 98 & \\
\hline & 9.21 & 10.6 & $<0.0001^{b}$ \\
\hline & 1.55 & 2.46 & $<0.0001^{\mathrm{b}}$ \\
\hline & 0.64 & 0.91 & $<0.0001^{b}$ \\
\hline \multirow{4}{*}{$\begin{array}{l}\text { Pre-exclusion cohort } \\
\text { IgG }<6.0 \mathrm{~g} / \mathrm{L} \\
\operatorname{lgA}<0.8 \mathrm{~g} / \mathrm{L} \\
\operatorname{lgM}<0.5 \mathrm{~g} / \mathrm{L}\end{array}$} & OR & $(95 \% \mathrm{Cl})$ & \\
\hline & 6.00 & $1.31-27.44$ & $0.0120^{c}$ \\
\hline & 16.75 & $2.18-128.6$ & $0.0002^{c}$ \\
\hline & 3.26 & $1.75-6.08$ & $0.0001^{\mathrm{C}}$ \\
\hline \multirow{4}{*}{$\begin{array}{l}\text { Post-exclusion cohort } \\
\text { IgG }<6.0 \mathrm{~g} / \mathrm{L} \\
\text { IgA }<0.8 \mathrm{~g} / \mathrm{L} \\
\text { IgM }<0.5 \mathrm{~g} / \mathrm{L}\end{array}$} & OR & $(95 \% \mathrm{Cl})$ & \\
\hline & 9.02 & $1.11-73.65$ & $0.0168^{c}$ \\
\hline & 32.63 & $1.91-558$ & $<0.0001^{c}$ \\
\hline & 2.86 & $1.42-5.73$ & $0.0040^{c}$ \\
\hline \multicolumn{4}{|c|}{$\begin{array}{l}\text { a. Values represent median serum immunoglobulin concentrations in } \mathrm{g} / \mathrm{L} \text {. Reference } \\
\text { range for } 5 \text { th to } 95 \text { th centiles in healthy adults: IgG, } 6.0-16 \mathrm{~g} / \mathrm{L} ; \mathrm{IgA}, 0.8-4.0 \mathrm{~g} / \mathrm{L} ; \mathrm{IgM}, \\
0.5-2.0 \mathrm{~g} / \mathrm{L} \\
\text { b. Mann-Whitney test. } \\
\text { c. Fisher's exact test. }\end{array}$} \\
\hline
\end{tabular}

clozapine-naive group (post-exclusion cohort) and shows a decline in serum IgG levels only in those receiving clozapine (Fig. 2).

To adjust for possible confounding variables that differed between groups (age, gender, diabetes, asthma/COPD, use of a second antipsychotic and diagnosis of schizophrenia) we performed linear regression analysis. Self-reported variables including current cigarette and alcohol consumption were similar between groups, although information on daily consumption was variably completed and considered vulnerable to reporting bias and were therefore not included. Medically documented diagnoses of asthma/COPD or diabetes were included as variables, as these conditions might theoretically be associated with use of immunosuppressive medication such as glucocorticoids not documented in available electronic general practitioner or psychiatric medical records.

Despite adjustment, there remained statistically significant immediate decreases in $\operatorname{IgA}(0.57 \mathrm{~g} / \mathrm{L}, P=0.01)$ and $\operatorname{IgM}(0.32 \mathrm{~g} / \mathrm{L}$, $P=0.02)$ and a significant association between decline in IgG and clozapine duration $(P=0.03)$, with a fall of serum $\operatorname{IgG}$ by $0.15 \mathrm{~g} / \mathrm{L}$ per year (supplementary Table 2). Serum IgA and IgM did not show a significant correlation with duration of antipsychotic use, potentially as a result of an earlier effect and that the lower limit of the reference range for $\operatorname{IgA}(0.8 \mathrm{~g} / \mathrm{L})$ and $\operatorname{IgM}(0.5 \mathrm{~g} / \mathrm{L})$ is closer to the sensitivity of nephelometric testing at $<0.24 \mathrm{~g} / \mathrm{L}$ for IgA and $<0.17 \mathrm{~g} / \mathrm{L}$ for IgM. Serum IgM decreased with age in both groups (not shown).

Using this model, we were also able to estimate the impact of clozapine duration on serum IgG levels following clozapine or non-clozapine antipsychotic medication use for an average 40year-old male, shown in supplementary Table 3 over a period of 25 years.

\section{Antibiotic usage and admission rates for infection}

Accepting the inherent shortcomings of self-reported data and the small number of reported events for the secondary outcomes of antibiotic usage and hospital admissions over the previous 12 months, the clozapine-treated group had higher antibiotic use, with a greater percentage of patients reporting more than five courses of antibiotics per year $5.3 \%(n=5)$ versus $1 \%(n=1)$ in

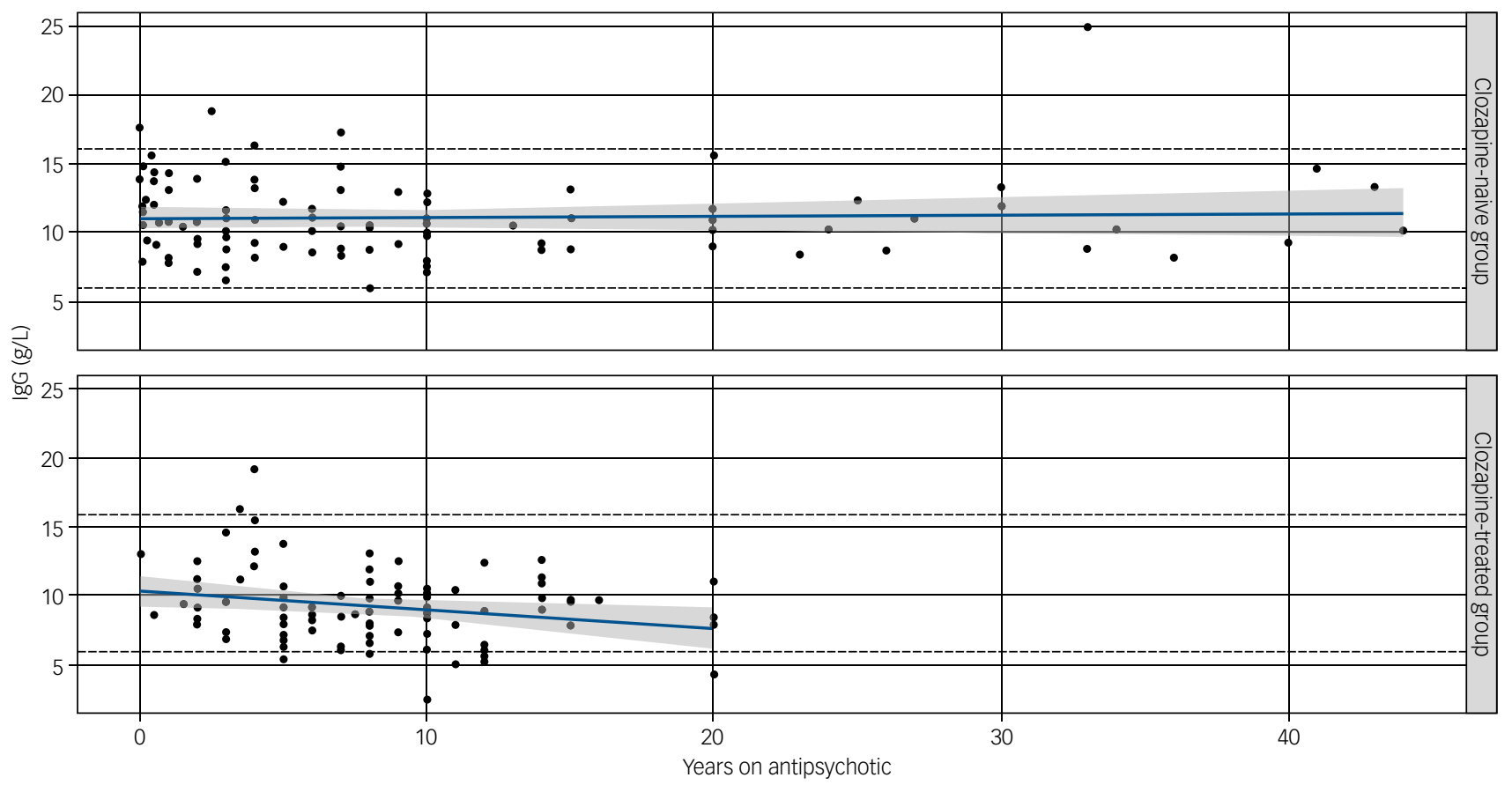

Fig. 2 Effect of duration of antipsychotic (upper) or clozapine (lower) treatment on immunoglobulin (Ig)G levels. A significant negative correlation of duration of clozapine use (years) was observed with an annual reduction in lgG levels of $0.15 \mathrm{~g} / \mathrm{L}(P=0.03)$ No correlation was seen with serum IgG level and non-clozapine antipsychotic medications $(P=0.14)$ despite a longer duration on therapy. Straight lines show predicted IgG at different durations of treatment (in years), based on fitted linear models. Shaded regions display pointwise $95 \%$ confidence intervals. 
the control group (Table 2). It was possible to validate hospital admissions by checking electronic medical records, thus reducing recall bias and allowing assessment of the admission trigger. There was a trend towards greater rate of confirmed infectionrelated admissions per patient year in the clozapine-treated group over the control group ( 8 versus 6 , respectively; equating to 0.08 versus 0.06 per patient year); however, this was not statistically significant. On an individual patient basis, these admissions clustered in four patients taking clozapine and occurred in six control patients.

\section{Discussion}

Clozapine is a dibenzo-diazepine atypical antipsychotic, and since 1990 the only licensed therapy in the UK for the $30 \%$ of patients with treatment-resistant schizophrenia. It shows superior efficacy in patients with schizophrenia and is effective in approximately $60 \%$ of those patients who were previously treatment refractive with a significant reduction in suicide risk. ${ }^{1,19}$ The National Institute for Health and Care Excellence guideline recommends that adults with schizophrenia that have not responded adequately to treatment with at least two antipsychotic drugs should be offered clozapine; however, evidence shows it to be underprescribed. ${ }^{1,20}$

In this study, we found that taking clozapine is associated with a significant and substantial reduction in serum immunoglobulins. Even following exclusion of other recognised potential causes of antibody deficiency, clozapine therapy was associated with $\operatorname{IgG}<6.0 \mathrm{~g} / \mathrm{L}$ in $8.5 \%, \operatorname{IgA}<0.8 \mathrm{~g} / \mathrm{L}$ in $13.8 \%$ and $\operatorname{IgM}<0.5 \mathrm{~g} / \mathrm{L}$ in $34 \%$ of the 94 patients. The magnitude of the reduction in immunoglobulins is considerable when compared with the percentages of patients with secondary antibody deficiency following long-term combination therapy with rituximab (a monoclonal antibody targeting B cells) and methotrexate for rheumatoid arthritis based on pooled data from the rituximab clinical trials programme: $\operatorname{IgG}<$ $6 \mathrm{~g} / \mathrm{L}$ in $3.5 \%, \operatorname{IgA}<0.8 \mathrm{~g} / \mathrm{L}$ in $1.1 \%$ and $\operatorname{IgM}<0.5 \mathrm{~g} / \mathrm{L}$ in $22.4 \% .{ }^{21}$ Our linear regression model suggests a lower initial IgG concentration ('lower reserve') is associated with an earlier approach to the lower limit of the reference range, which is in keeping with known risk factors for secondary antibody deficiency following immunosuppressive therapies such as steroids and rituximab. ${ }^{22}$ In general, the greater the fall in IgG level below the lower limit of the reference range, the greater the probability of infections. Early diagnosis of antibody deficiency enables prevention of chronic infection, sepsis, end organ damage and death. ${ }^{23}$

\section{Strengths and limitations of this study}

Limitations of this work include the lack of prospective data, duration of follow-up and study size. In addition, there are shortcomings inherent in self-reported data and research officers administered the questionnaire and thus were not masked to participant medications. The width of confidence intervals presented alongside odds ratios reflect the relatively small sample size and low numbers of patients with values below the threshold for IgG, IgA or IgM used in both groups. Despite this, a higher proportion of patients needing more than five antibiotic courses in 12 months was seen in the clozapine recipients within this study, in keeping with previously reported increased antibiotic use.

Despite these limitations, all odds ratios were above one for total immunoglobulin classes and were highly statistically significant. These findings remained despite rigorous exclusion of patients with known possible causes of antibody deficiency. ${ }^{17}$ This is a strength and limitation of this study. Our aim was to reduce potential bias, however, the evidence for associations between medications such as carbamazepine or valproate and hypogammaglobulinaemia are largely based upon case reports. Exclusion of these patients may therefore result in an underestimate of the true effect size, particularly if drug interactions can contribute to immunoglobulin deficiency. Given a potential effect of smoking on IgG levels, ${ }^{24}$ we assessed self-reported current smoking status. This represents a subjective measure of smoking frequency, however, prevalence was high, similar between groups (61\% versus $56 \%$ ), and in keeping with that reported elsewhere. ${ }^{25}$ It is notable that the significant association between duration of antipsychotic treatment and reduction in IgG was not observed in the clozapine-naive group, despite a longer duration of exposure to other antipsychotic agents and was not accounted for by other factors such as age, gender, diabetes, diagnosis of asthma/COPD, use of second antipsychotic agent, or psychiatric diagnosis in linear regression modelling.

A number of serious adverse effects including seizures, intestinal obstruction, diabetes, thromboembolism, cardiomyopathy and sudden cardiac death have been described with clozapine. It has been postulated that some of these side-effects may relate to its immunomodulatory effects, ${ }^{26}$ including agranulocytosis (cumulative incidence $0.8 \%) .{ }^{27} \mathrm{An}$ association of clozapine with selective IgM deficiency has previously been suggested ${ }^{28}$ identifying isolated IgM deficiency in six (18\%) clozapine users and two controls (3\%). Differences in study size, treatment duration, and the differential effect on immunoglobulin classes ( $\operatorname{IgM}>\operatorname{IgA}>\operatorname{IgG})$ might have contributed to the identification of the greater risks posed by reductions in all three immunoglobulin classes reported here.

An additional strength of our study was detailed immunological assessment of vaccine-specific responses, which are integral components of patient evaluation and risk stratification during assessment of humoral immunodeficiency. ${ }^{29}$ The majority of patients in both the clozapine and control groups had baseline specific antibody levels below the protective range for pneumococcus and haemophilus, common respiratory tract pathogens. This is in contrast to the majority of patients still having immunoglobulin levels within the reference range (albeit significantly lower than controls for all three classes) and likely reflects similarities between the groups in terms of the combination of prior vaccination history and natural exposure to these pathogens. This suggests that the population as a whole might benefit from improved access to vaccination, particularly given the numerous additional risk factors (smoking, diabetes, alcohol intake, illicit drug use, poor diet and physical inactivity) they may encounter.

The clozapine-treated group differed significantly from controls with lower levels of IgA and IgM pneumococcal antibodies. IgA is involved in defence against infection at mucosal surfaces such as the upper and lower respiratory tract and gut. The reasons why IgA and IgM pneumococcal antibodies were lower in the clozapine-treated group is not entirely clear but may reflect the greater relative and more immediate reductions in total IgA and IgM compared with IgG relative to the healthy adult and control group range.

\section{Implications}

This work, if confirmed, has potential implications for monitoring and risk mitigation strategies surrounding use of this important medication. This is particularly relevant given recent changes to the United States Clozapine Risk Evaluation and Mitigation Strategy programme (www.clozapinerems.com) that includes lowering the absolute neutrophil count threshold at which interruption of clozapine treatment is required. The impact of these changes will allow greater flexibility in patient-specific decisions about continuing or resuming treatment in patients who develop moderate to 
severe neutropenia, and so increase access to clozapine in patients across the USA.

Further studies are urgently required to validate these findings of immunoglobulin deficiency in a wider population of patients receiving clozapine, and to address questions relating to causality. These should be sufficiently powered to assess the impact of clozapine dose and duration, and explore additional risk factors such as concomitant medication, dual antipsychotic use, initial pre-clozapine immunoglobulin levels, smoking levels, durability of vaccine responses and any impact of schizophrenia itself. If confirmed there are also potential implications for practice, as current monitoring schemes do not include immunoglobulin testing. Given routine neutrophil monitoring and the centralised-nature of registries, integration of immunoglobulin and specific antibody level testing would be relatively straightforward. This would allow identification, risk stratification and monitoring of changes over time with individualised intervention where needed.

The association between duration of clozapine use and reduction in IgG suggests that long-term monitoring may be needed. In addition, the results highlight the wider issue of protecting this vulnerable patient group from infection, irrespective of clozapine treatment, by optimising vaccination status. This could be improved by formally defining this population as a risk group (as is the case for pneumococcal vaccination for patients with chronic lung disease, chronic heart disease, splenectomy and diabetes) to ensure equitable and appropriate access to protection via vaccination.

Mark Ponsford, MBChB, MRCP, Immunology Specialist Registrar, Immunodeficiency Centre for Wales, University Hospital of Wales and Welsh Clinical Academic Trainee, Cardiff University, UK; Daniel Castle, MBChB, Neurology Specialist Registrar, Immunodeficiency Centre for Wales, University Hospital of Wales, UK; Tayyeb Tahir FRCPsych, MD, Professor of Psychiatry, Department of Liaison Psychiatry, University Hospital of Wales, UK; Rebecca Robinson, MSc, Research Officer, Health and Care Research Wales, University Hospital of Wales, UK; Wendy Wade, Research Manager, Health and Care Research Wales, University Hospital of Wales, UK; Rachael Steven, PhD, Immunology Clinical Scientist, Immunodeficiency Centre for Wales, University Hospital of Wales, UK: Kathryn Bramhall, BSC, Immunology Biomedical Scientist, Immunodeficiency Centre for Wales, University Hospital of Wales, UK; Mo Moody, BSC, Immunology Biomedical Scientist, Immunodeficiency Centre for Wales, University Hospital of Wales, UK; Emily Carne, MSc, Immunology Clinical Nurse Specialist, Immunodeficiency Centre for Wales, University Hospital of Wales, UK; Catherine Ford BSC, Mental Health Nurse, Community Mental Health Team, University Hospital of Wales, UK; Daniel Farewell, MMath, PhD, Reader, Division of Population Medicine, School of Medicine, College of Biomedical and Life Sciences, Cardiff University, UK: Paul Williams, FRCP, FRCPath, PhD, Consultant Immunologist, Immunodeficiency Centre for Wales, University Hospital of Wales, UK; Tariq El-Shanawany, MRCP, FRCPath, MD, Consultan Immunologist, Immunodeficiency Centre for Wales, University Hospital of Wales, UK: Stephen Jolles, FRCP, FRCPath, PhD, Professor of Clinical Immunology, Immunodeficiency Centre for Wales, University Hospital of Wales, UK

Correspondence: Stephen Jolles, Immunodeficiency Centre for Wales, University Hospital of Wales, Heath Park, Cardiff CF14 4XW, UK. Email: jollessr@cardiff.ac.uk

First received 12 Feb 2018, final revision 20 May 2018, accepted 1 Jul 2018

\section{Funding}

Health and Care Research Wales, CSL Behring and The Binding Site.

\section{Acknowledgements}

This portfolio observational study was supported by Health and Care Research Wales research officers and support for laboratory consumables was provided by The Binding Site and CSL Behring. The huge support of staff at all of the community mental health teams is very gratefully acknowledged. Thank you also to Dr Jenny Hughes for careful reading of the manuscript.

\section{Supplementary material}

Supplementary material is available online at https://doi.org/10.1192/bjp.2018.152.

\section{References}

1 Owen MJ, Sawa A, Mortensen PB. Schizophrenia. Lancet 2016; 388: 86-97.

2 Hor K, Taylor M. Suicide and schizophrenia: a systematic review of rates and risk factors. J Psychopharmacol 2010; 24 (4 suppl): 81-90.

3 Tiihonen J, Lonnqvist J, Wahlbeck K, Klaukka T, Niskanen L, Tanskanen A, et al. 11-year follow-up of mortality in patients with schizophrenia: a populationbased cohort study (FIN11 study). Lancet 2009; 374: 620-7.

4 Copeland LA, Mortensen EM, Zeber JE, Pugh MJ, Restrepo MI, Dalack GW. Pulmonary disease among inpatient decedents: impact of schizophrenia. Prog Neuropsychopharmacol Biol Psychiatry 2007; 31: 720-6.

5 Walker AM, Lanza LL, Arellano F, Rothman KJ. Mortality in current and former users of clozapine. Epidemiology 1997; 8: 671-7.

6 Hung GC, Liu HC, Yang SY, Pan CH, Liao YT, Chen CC, et al. Antipsychotic reexposure and recurrent pneumonia in schizophrenia: a nested case-control study. J Clin Psychiatry 2016; 77: 60-6.

7 Leung JG, Hasassri ME, Barreto JN, Nelson S, Morgan 3rd RJ. Characterization of admission types in medically hospitalized patients prescribed clozapine. Psychosomatics 2017; 58: 164-72.

8 Stoecker ZR, George WT, O'Brien JB, Jancik J, Colon E, Rasimas JJ. Clozapine usage increases the incidence of pneumonia compared with risperidone and the general population: a retrospective comparison of clozapine, risperidone, and the general population in a single hospital over 25 months. Int Clin Psychopharmacol 2017; 32: 155-60.

9 Kuo CJ, Yang SY, Liao YT, Chen WJ, Lee WC, Shau WY, et al. Second-generation antipsychotic medications and risk of pneumonia in schizophrenia. Schizophr Bull 2013; 39: 648-57

10 Mustafa FA, Burke JG, Abukmeil SS, Scanlon JJ, Cox M. 'Schizophrenia past clozapine': reasons for clozapine discontinuation, mortality, and alternative antipsychotic prescribing. Pharmacopsychiatry 2015; 48: 11-4.

11 Taylor DM, Douglas-Hall P, Olofinjana B, Whiskey E, Thomas A. Reasons for discontinuing clozapine: matched, case-control comparison with risperidone long-acting injection. Br J Psychiatry 2009; 194: 165-7.

12 Abdelmawla N, Ahmed MI. Clozapine and risk of pneumonia. Br J Psychiatry 2009; 194: 468-9.

13 Bello S, Menendez R, Torres A, Reyes S, Zalacain R, Capelastegui A, et al. Tobacco smoking increases the risk for death from pneumococcal pneumonia. Chest 2014; 146: 1029-37

14 Jolles S, Borrell R, Zouwail S, Heaps A, Sharp H, Moody M, et al. Calculated globulin (CG) as a screening test for antibody deficiency. Clin Exp Immunol 2014; 177: 671-8.

15 Jolles S. The variable in common variable immunodeficiency: a disease of complex phenotypes. J. Allergy Clin Immunol Pract 2013; 1: 545-56.

16 Milford W. A., Joanna S., Rowbottom A, Wild GD. Handbook of Clinical Immunochemistry (9th edn). PRU Publications, 2007.

17 European Society of Immunodeficiences. Diagnostic Criteria for Primary Immunodeficiency. ESID, no date (https://esid.org/Working-Parties/Clinical/ Resources/Diagnostic-criteria-for-PID2\#Q6).

18 Chua I, Lagos M, Charalambous BM, Workman S, Chee R, Grimbacher B. Pathogen-specific IgG antibody levels in immunodeficient patients receiving immunoglobulin replacement do not provide additional benefit to therapeutic management over total serum IgG. J Allergy Clin Immunol 2011; 127: 1410-1.

19 Meltzer HY, Alphs L, Green Al, Altamura AC, Anand R, Bertoldi A, et al. Clozapine treatment for suicidality in schizophrenia: international Suicide Prevention Trial (InterSePT). Arch Gen Psychiatry 2003; 60: 82-91.

20 National Institute for Health and Care Excellence. Psychosis and Schizophrenia in Adults: Prevention and Management.NICE, 2014.

21 van Vollenhoven RF, Emery P, Bingham 3rd CO, Keystone EC, Fleischmann RM, Furst $D E$, et al. Long-term safety of rituximab in rheumatoid arthritis: 9.5-year follow-up of the global clinical trial programme with a focus on adverse events of interest in RA patients. Ann Rheum Dis 2013; 72: 1496-502.

22 Christou EAA, Giardino G, Worth A, Ladomenou F. Risk factors predisposing to the development of hypogammaglobulinemia and infections post-Rituximab. Int Rev Immunol 2017; 36: 352-9.

23 Resnick ES, Moshier EL, Godbold JH, Cunningham-Rundles C. Morbidity and mortality in common variable immune deficiency over 4 decades. Blood 2012; 119: 1650-7.

24 McMillan SA, Douglas JP, Archbold GP, McCrum EE, Evans AE. Effect of low to moderate levels of smoking and alcohol consumption on serum immunoglobulin concentrations. J Clin Pathol 1997; 50: 819-22.

25 Kelly C, McCreadie RG. Smoking habits, current symptoms, and premorbid characteristics of schizophrenic patients in Nithsdale, Scotland. Am J Psychiatry 1999; 156: 1751-7. 
26 Roge R, Moller BK, Andersen CR, Correll CU, Nielsen J. Immunomodulatory effects of clozapine and their clinical implications: what have we learned so far? Schizophr Res 2012; 140: 204-13.

27 Alvir JM, Lieberman JA, Safferman AZ, Schwimmer JL, Schaaf JA. Clozapineinduced agranulocytosis. Incidence and risk factors in the United States. N Engl J Med 1993; 329: 162-7.

28 Lozano R, Marin R, Santacruz MJ, Pascual A. Selective immunoglobulin M deficiency among clozapine-treated patients: a nested case-control study. Prim Care Companion CNS Disord 2015; 17: 10.4088/PCC.
29 Jolles S, Chapel H, Litzman J. When to initiate immunoglobulin replacement therapy (IGRT) in antibody deficiency - a practical approach. Clin Exp Immunol 2016; 188: 333-41.

\section{psychiatry in history}

\section{Bernardino Álvarez and the origins of psychiatric care in America}

\section{Fernando Espí Forcén}

Bernardino Álvarez was born in Seville, Spain in 1514. At the age of 20, after receiving military training, he migrated to the New World to serve for the Spanish crown in the Chichimeca conflict located in the region of Zacatecas (North-Central México). Once relieved of his military duties, he encountered trouble with the law as a result of his gambling activity and was imprisoned. surprisingly, he escaped to Peru where he lived for a number of years and became wealthy.

Upon his return to México-Tenochtitlan, and after finding out about the death of his father, he wrote to his mother inviting her to join him with his siblings in the New World where he was living comfortably. However, his mother replied stating that she was financially stable and she encouraged him to live a pious life. This letter from his mother inspired Bernardino to become a friar and dedicate his life to helping the sick and poor. Having observed how hospitals in the city were crowded and that patients were often discharged before they had recovered, he collected funds for the foundation of a new hospital with larger capacity.

In 1567 the Archbishop of the city, friar Alonso de Montufar, gave Bernardino permission to build the new hospital and designated the location of it next to the Church of San Hipólito, which provided the new facility with its name. Throughout the years Bernardino collected money to expand the hospital. Soon, it welcomed not only the sick and poor but people with intellectual disabilities and severe mental illness (then called 'innocents' and 'mad'). Bernardino thought patients with mental illness could learn virtue from mentally healthy people, thus, he developed the idea of putting patients deprived of reason together with others who exhibited stable mental health. He also emphasised the importance of exercise and diet as a means of recovery in this population. Following the success of the new hospital and the model Bernardino had created for it, he founded a network of similar hospitals in Acapulco, Puebla and Veracruz in México and La Havana in Cuba. All of them were connected.

After Bernardino's death, the Hospital of San Hipólito hired their first physician in 1590, Don José de Cabas. In the modern era, patients with mental illness received medical treatment based on the principles of Hippocratic and Galenic medicine. Thus, good diet, exercise and purging were often prescribed. Friars were also involved in patient care and assisted patients with spiritual care, support and occupational therapy. The hospital tended to patients from all origins and ethnicities, including people with African, Native and Spanish roots. The Hospital of San Hipólito remained active focusing mainly on the treatment of the mentally ill in México over several centuries until the opening of the La Castañeda Mental Asylum in 1910. Today, the original building of San Hipólito is still standing and open to visitors. In accordance with 16th century architectural style, its structure includes a twofloor cloister with a central fountain.

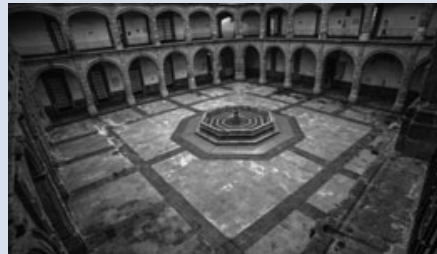

The Hospital of San Hipólito represents an early example of medical care for mentally ill people in the so-called 'New Continent' Its approach to the treatment of mental health followed the tradition of other Spanish hospitals for the mentally ill, such as, Valencia (1410), Saragossa (1425), Seville (1436) and Toledo (1480). Before the Enlightenment, a medical approach to mental illness existed in the Hispanic world. San Hipólito's innovative approach to mental illness during this time helps us elucidate the origins of psychiatric care in America.

\section{Acknowledgements}

Thank you to Ana Everaert Usobiaga and Pablo Usobiaga at the Ex-Convent of San Hipólito for sharing the image of San Hipólito and giving permission for publication. In addition, thanks to Kim Morley for help with editing. 